\title{
Eficiência do aguapé sobre variáveis limnológicas em canais de abastecimento utilizados no cultivo de tambaqui
}

\author{
Alinne Dué Ramos da SILVA ${ }^{1}$, Robson Batista dos SANTOS ${ }^{2 *}$, Arthur Murilo da Silva Souza BRUNO², \\ André Luis GENTELINI², Ana Helena Gomes da SILVA³ ${ }^{3}$ Emerson Carlos SOARES ${ }^{2}$ \\ 1 Universidade Federal de Alagoas (UFAL). Programa de Pós Graduação em Diversidade Biológica e Conservação nos Trópicos, DiBicT, ICBS. Praça Afrânio Jorge, s/n. Centro, \\ Prado, CEP: 57000-000. Maceió, Alagoas, Brasil. alinne_due@hotmail.com. \\ 2 Universidade Federal de Alagoas (UFAL). Departamento de Engenharia de Pesca, campus Arapiraca-Pólo Penedo. Av. Beira Rio, S/n, CEP: 57200-000. Penedo, Alagoas, Brasil. \\ rob.dja@bol.com.br. arthurmurilo@gmail.com, andregentelini@hotmail.com, soaemerson@gmail.com \\ ${ }^{3}$ Companhia de Desenvolvimento dos Vales do São Francisco e do Parnaíba (CODEVASF). Centro Integrado de Recursos Pesqueiros e Aquicultura do Betume, 4a/CIB, 4aSR, CEP: \\ 49980-000. Neópolis, Sergipe, Brasil. ana.helena@codevasf.gov.br \\ * Autor Correspondente: rob.dja@bol.com.br
}

\section{RESUMO}

O uso de macrófitas aquáticas pode ser uma alternativa para o tratamento e minimização dos efluentes gerados na piscicultura. Objetivou-se com este trabalho verificar a eficiência do aguapé (Eichhornia crassipes) na melhora de variáveis limnológicas (fósforo e amônia) com cultivo de tambaqui (Colossoma macropomum) em canais com fluxo contínuo de água. O experimento foi conduzido por um período de 60 dias com amostragens quinzenais em canais de abastecimento, seccionados com telas e utilizando uma densidade de 120 peixes $\mathrm{m}^{-3}$. As seçôes foram divididas em etapas, alternando com presença e/ou ausência de aguapé. Não foram constatadas diferenças significativas nos teores de amônia, alcalinidade e dureza do efluente, nos tratamentos com ou sem a presença dos aguapés, contudo foi comprovada a eficiência do aguapé na remoçáo de nutrientes como o fósforo nas primeiras semanas de cultivo, sendo recomendado, o seu uso em sistemas de criação de peixes.

PALAVRAS-CHAVE: Eichhornia crassipes, fósforo, amônia, qualidade de água

\section{Biofilter efficiency of water hyacinth on limnological variables in irrigation channels used for tambaqui farming}

\section{ABSTRACT}

The use of biofilter of aquatics plants can be an alternative for the treatment and minimization of effluents generated in fish farming. The objective of this work was to evaluate the effect of water hyacinth (Eichhornia crassipes) in the improvement of the limnological variables of water of supply channels used for fish farming. The experiment was conducted in supply channels over a period of 60-days at sampling intervals of fifteen days. The channels were sectioned with screens. A density of 120 fish $\mathrm{m}^{-3}$ was used. The sections were divided into stages, alternating with presence or absence of water hyacinth. It was not observed significant differences in the level of ammonia ( $p>0.05)$, alkalinity and hardness of the effluent in both treatment systems. However it was observed that water hyacinth was efficient in the removal of nutrients such as, phosphorus (first weeks of cultivation). The use of water hyacinth can be recommended in fish farming systems.

KEYWORDS: Eichhornia crassipes, phosphorus, ammonia, water quality 


\section{INTRODUÇÃO}

A aquicultura contribui para modificação nas características físicas e químicas dos corpos d'água por meio de resíduos sólidos orgânicos e nutrientes, como nitrogênio e fósforo, proveniente principalmente, das sobras de raçóes e das excretas dos animais (Henry-Silva e Camargo 2006).

O descarte direto e contínuo dos efluentes de aquicultura pode resultar em acumulação crônica de resíduos, levando ao processo de eutrofização artificial, com consequências ecológicas negativas sobre o ambiente (Macedo e SipaúbaTavares 2010). Desse modo, há a necessidade da busca por alternativas que auxiliem na diminuiçáo do impacto no meio aquático provenientes de sistemas de cultivo intensivos e semi-intensivos com densidades elevadas, onde altas taxas de nutrientes, provenientes da alimentação são utilizadas (Sipaúba-Tavares et al. 2003).

Uma alternativa para o tratamento e minimização dos efluentes gerados na piscicultura vem sendo proposta por vários autores, onde o uso de biofiltros composto por macrófitas aquáticas parece ser uma solução barata e viável (Sipaúba-Tavares et al. 2002, 2003; Crema 2005; Ferdoushi et al. 2008). As principais vantagens dos sistemas de filtros com macrófitas aquáticas são o baixo custo de implementaçáo e manutençáo, e a comprovada eficiência no tratamento de diversos tipos de efluentes (Klomjek e Nitisoravut 2005). Adicionalmente, a biomassa produzida pode ser aproveitada na produção de biogás na alimentação animal e como fertilizante na agricultura (Henry-Silva e Camargo 2002; Pompêo 2008).

O aguapé (Eichhornia crassipes) é uma macrófita aquática emersa flutuante originária da regiâo amazônica (Martins e Pitelli 2005). A espécie prolifera rapidamente em lagos com elevadas concentraçôes de nutrientes (eutrofizados), utilizados em seu metabolismo, e tem a capacidade de remover metais pesados e outros contaminantes da água (Gonçalves Júnior et al. 2008).

O aguapé vem sendo aplicado nos tratamentos de efluentes, tanto industrial como agropecuários, inclusive na aquicultura (Henry-Silva e Camargo 2006). Segundo HenrySilva e Camargo (2006) E. crassipes foi uma das macrófitas aquáticas que apresentaram maior eficiência na melhoria da qualidade dos efluentes. Além disso, Gentelini et al. (2008) recomendam o aguapé no tratamento da água em sistemas de cultivo de peixes.

O uso destas plantas em canais de abastecimento de água com cultivo de tambaquis (peixes rústicos e disseminados em programas no Nordeste) pode ser uma solução sustentável, já que, canais apresentam construção de fácil execução e sua estrutura encontra-se terminada (com finalidade de irrigaçāo), proporciona a diminuição do estresse nas etapas de manejo, facilidade de manuseio e monitoramento das condiçóes gerais dos organismos, além de possibilitar alta taxa de renovaçáo de água e carreamento de nutrientes, sendo uma alternativa de sucesso para a piscicultura moderna (Redding e Midlen 1992; Arbeláez-Rojas et al. 2002; Lima et al. 2008).

Por outro lado o uso de canais de abastecimento visa o transporte de água com a premissa inicial de atender a irrigação de culturas, portanto a multiplicidade de seu uso pode gerar alguns conflitos, e desta forma, questôes como manejo e gerenciamento hídrico podem ser decisivos ou dificultar a sustentabilidade deste sistema usado no cultivo de peixes em regiôes do semi-árido (Redding e Midlen 1992).

O objetivo do trabalho foi verificar a eficiência do aguapé, E. crassipes, na melhora de variáveis limnológicas para o cultivo de juvenis de tambaquis (Colossoma macropomum) em canais com fluxo contínuo de água.

\section{MATERIAL E MÉTODOS}

O estudo foi conduzido no Centro Integrado de Recursos Pesqueiros e Aqüicultura do Betume da Companhia de Desenvolvimento dos Vales do São Francisco e do Parnaíba (CODEVASF), localizada no município de Neópolis, Sergipe, no período 13 de maio a 15 de agosto de 2010 .

Após o período de aclimatação, correspondente a nove dias, 4.320 juvenis de tambaqui oriundos de quatro desovas intercaladas foram selecionados, medidos e pesados de forma que fossem distribuídos homogeneamente $(10,6 \pm 1,0 \mathrm{~cm}$ de comprimento padrão médio; $49,5 \pm 2,8 \mathrm{~g}$ de peso médio) em uma densidade de 120 peixes $\mathrm{m}^{-3}$ por secção de canal $\left(1,0 \mathrm{~m}^{3}\right)$ em cada etapa quinzenal. Os indivíduos foram alimentados com duas porçôes diárias (8:30h e 16:30h) correspondendo a $5 \%$ da biomassa viva, utilizando raçáo extrusada comercial (Nutron), contendo 32\% (mínimo) de proteína bruta, umidade de 12\% (máximo), 4\% (mínimo) de extrato etéreo, $12 \%$ (máximo) de matéria mineral, $8 \%$ (máximo) de material fibroso, $2 \%$ (máximo) de cálcio e $0,6 \%$ (mínimo) de fósforo.

$\mathrm{O}$ experimento foi realizado em canal de abastecimento utilizando $20 \mathrm{~m}$ de extensão apresentando formato trapezoidal com as seguintes dimensões: $1,50 \mathrm{~m}$ altura $\times 1,40 \mathrm{~m}$ base maior x $0,35 \mathrm{~m}$ base menor e vazão controlada $\left(4.500 \mathrm{~L} \mathrm{~h}^{-1}\right)$. O canal foi seccionado em dezesseis ambientes de cultivo $\left(1,0 \mathrm{~m}^{3}\right)$, dos quais nove destes foram destinados ao acondicionamento de peixes e os sete restantes intercalaram com três áreas destinadas às zonas de alívio (áreas destinadas à renovação de água), três áreas destinadas à utilizaçáo de macrófitas aquáticas e uma secçáo destinada à determinaçáo dos efluentes provenientes das secções que não continham zonas de alívio e macrófitas aquáticas.

As telas de arame ( $4,0 \mathrm{~cm}$ entre nós) usadas nas secçôes experimentais (volume útil de $0,90 \mathrm{~m}^{3}$ ) eram revestidas por zinco e PVC e costuradas em armaçáo de aço dispostas e 
niveladas no canal. Adicionalmente foram colocadas redes secundárias (tela de segurança e rede anti-pássaro) para retençâao de peixes no caso de fuga ou predação por aves. Durante o experimento, as telas foram limpas semanalmente para evitar a formação do perifíton, retenção de detritos orgânicos e partículas inorgânicas associadas. Paralelamente, após cada fase experimental, o sistema de cultivo passou por um processo de limpeza e renovação de água, minimizando possíveis incertezas e influências decorrentes da mudança de tratamento.

Foi avaliado o cultivo com e sem a presença de aguapés. A condução do experimento se deu em quatro etapas intercaladas quinzenalmente, devido ao período de senescência, (nutrientes podem ser liberados para o meio pelo processo de decomposição), onde as macrófitas e os peixes eram substituídos por novas exemplares e dispostos no seguinte formato: da primeira a quarta quinzenas - presença de peixes com secções de alívio (sem aguapé) (tratamento 1), presença de peixes com secções com aguapé (tratamento 2) e presença de peixes sem secçôes de alívio (tratamento 3), com três repetiçôes a cada quinze dias seguindo um delineamento inteiramente casualizado (Figura 1).

Ao final de cada quinzena a vazáo do canal foi aumentada por dois dias para propiciar a limpeza dos detritos antes de começar a outra etapa do experimento. Embora a vazáo do canal de abastecimento tenha se mantido constante durante todo o tempo do estudo, foi necessário um pequeno ajuste do fluxo de água em curto espaço de tempo (dois dias em cada quinzena experimental) para atender a demanda de viveiros de piscicultura e cultivos de hortaliças localizadas ao longo da estrutura.

O aguapé (Eichhornia crassipes, (Martius) Solms-Laubach, Pontederiaceae) foi coletado na margem do rio São Francisco em frente à estaçáo de piscicultura, sendo ambientado por um período de 10 dias em duas secçóes separadas da área do experimento no canal. A biomassa de macrófita inicial de cada secção correspondeu a $80 \%$ da área da unidade experimental (Henry-Silva e Camargo 2006), totalizando $14 \mathrm{~kg}$ de peso fresco por $\mathrm{m}^{2}$ e foi descartado e reposto a cada quinzena do experimento.

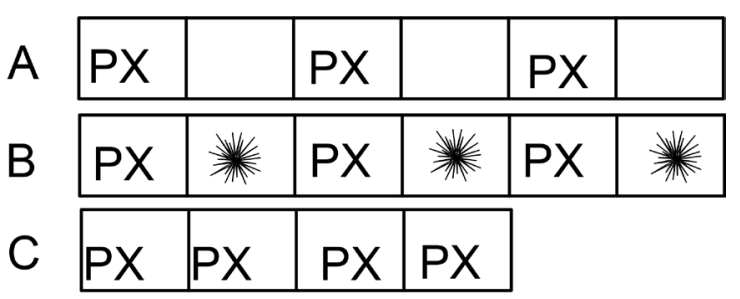

Figura 1 - Esquema de distribuição das secções experimentais: A - tratamento 1 (peixes com secção de alívio), B - Tratamento 2 (peixes com secções com macrófitas aquáticas) e $\mathrm{C}$ - Tratamento 3 (peixes sem secções de alívio e sem secções com macrófitas)
O efluente foi mensurado e monitorado na entrada e saída de cada secçáo em dois horários (8:00h e 16:00h) da seguinte forma: temperatura $\left({ }^{\circ} \mathrm{C}\right)$ e oxigênio dissolvido $\left(\mathrm{mg} \mathrm{L}^{-1}\right)$ (diariamente), por meio de um oxímetro (Hanna Instrutherme, MO-900, Woonsocket, USA) e sonda multiparâmetro (Hanna, HI 9828, Woonsocket, USA). Alcalinidade total $\left(\mathrm{mg} \mathrm{L}^{-1}\right)$, dureza $\left(\mathrm{mg} \mathrm{L}^{-1}\right), \mathrm{pH}$ amônia total ( $\left.\mathrm{mg} \mathrm{L}^{-1}\right)$ e nitrito $\left(\mathrm{mg} \mathrm{L}^{-1}\right)$, por meio de um espectofotômetro e fósforo e nitrogênio $\left(\mathrm{mg} \mathrm{L}^{-1}\right)$ avaliados a cada cinco dias conforme método Kjeldahl e fotocolorimetria (APHA1995).

As porcentagens de remoção de amônia e fósforo foram calculadas de acordo com Henry-Silva e Camargo (2008) pela Equaçáo 1:

$$
\mathrm{R}=100-\left[\left(100 \times \mathrm{C}_{\text {etrat }}\right) / \mathrm{C}_{\mathrm{e}}\right](\text { Eq. } 1)
$$

em que: $\mathrm{R}$ - porcentagem de remoção; $\mathrm{C}_{\text {etrat }}$ - concentraçáo de nutriente no efluente tratado com aguapé e $\mathrm{C}_{e}$ concentraçáo de nutriente no efluente tratado sem aguapé.

Ao final de cada quinzena com aguapés, estes foram removidos das secções para a determinação da produção da biomassa vegetal, estimada a partir da diferença entre o peso final e inicial. Antes da pesagem, foi retirado o excesso de água retida nas raízes dos vegetais, deixando-se a água escoar por aproximadamente 5 minutos.

Os efluentes foram avaliados e contabilizados em dois horários (8:00 e 16:00h). A homogeneidade do lote de peixes após pesagem no início de cada quinzena do experimento foi analisada pelo teste de Cochran a $5 \%$ de probabilidade. O erro experimental quanto ao período quinzenal foi minimizado devido os exemplares utilizados no experimento apresentarem os comprimentos e pesos similares em todas as etapas experimentais (quatro quinzenas). Adicionalmente, as técnicas de controle local, homogeneidade das amostras, casualizaçáo e independência entre as secçôes foram testadas e abordadas em um experimento piloto nas mesmas condiçóes do presente trabalho, permitindo assim o uso da ANOVA- one way em detrimento de uma ANOVA com medidas repetidas no tempo.

Os resultados obtidos quanto aos parâmetros físicoquímicos da água, níveis de fósforo e amônia e desempenho dos peixes no estudo foram submetidos à análise de variância, a 5\% de significância. Quando "F" foi significativo, utilizouse teste Tukey a $5 \%$. Adicionalmente, foi utilizado o teste de Bonferroni $(\mathrm{p}<0,05)$, com a finalidade de verificar médias de variáveis isoladas.

\section{RESULTADOS}

Ao término do período experimental (a cada 15 dias), os juvenis de tambaquis amostrados apresentaram comprimento padrão médio de $12,2 \pm 1,21 \mathrm{~cm}$, peso médio de $59,2 \pm 2,01 \mathrm{~g}$, crescimento específico em peso diário de $1,0 \%$ e sobrevivência de $100 \%$. 
No decorrer do período experimental, menores valores de temperatura $\left(26,5 \pm 0,6\right.$ e $\left.28,1 \pm 0,8^{\circ} \mathrm{C}\right)$ foram observados no horário da manhã (média de $27,0 \pm 0,4^{\circ} \mathrm{C}$ ) e nas secçôes sem a presença do aguapé, enquanto que no horário da tarde $\left(29,0 \pm 0,6^{\circ} \mathrm{C}\right)$ e nas unidades com macrófitas os valores foram maiores $\left(27,9 \pm 0,8\right.$ e $\left.29,2 \pm 1,0{ }^{\circ} \mathrm{C}\right)$.

Houve diferenças significativas nas concentraçóes de oxigênio dissolvido entre os horários de avaliaçấo e entre as interaçôes quinzena $\mathrm{x}$ horário. As 16:00 h foram encontrados maiores valores desta variável $\left(6,6 \mathrm{mg} \mathrm{L}^{-1}\right)$ em detrimento do horário da manhã $\left(6,0 \mathrm{mg} \mathrm{L}^{-1}\right)$. Adicionalmente, embora teores deste parâmetro tenham obtido pequena elevaçáo nas duas primeiras quinzenas (teste de Tukey, não significativo, $p=0,60$, entre estas duas primeiras quinzenas), estes náo foram significativos com relaçâo ao último mês do experimento e obtiveram valores acima de $6,0 \mathrm{mg} \mathrm{L}^{-1}$, independentemente do horário de coleta.

Durante o período experimental, o $\mathrm{pH}$ não apresentou variaçôes acentuadas. O efluente tratado com aguapé exibiu menores valores quando comparados com os tratamentos sem aguapé e com e sem secção de alívio (os dois últimos tratamentos não apresentaram diferenças significativas entre si), e foi levemente ácido no período da manhã. Este mesmo padrão foi observado para a dureza da água, que obtiveram menores valores $\left(20,17 \pm 2,12\right.$ e $\left.22,16 \pm 2,10 \mathrm{mg} \mathrm{L}^{-1}\right)$ quando o efluente foi tratado por macrófitas aquáticas.

Não foram constatadas diferenças significativas ( $p>0,05)$ entre as quinzenas do experimento, secçóes de estudo e tratamentos com presença de macrófitas, ausência de macrófitas com secção de alívio e sem macrófitas e secção de alívio para as variáveis; amônia e alcalinidade. Durante todo o período estudado foram encontrados valores muito baixos de amônia, nitrito e nitrato nas unidades experimentais, sendo estes não significativos para os tratamentos analisados. Tal fato pode estar relacionado ao tempo de residência da água (hidrodinâmica) que favorece o carreamento de metabólitos para fora da área de cultivo (Tabela1 e Figura 2).

Avaliando-se o efeito isolado do teor de fósforo com relaçáo à quinzena de estudo, ocorreram diferenças significativas na primeira e terceira quinzena de cultivo (presença de aguapé) em relaçấo às demais, contudo, os maiores valores desta variável foram encontrados nos dois tratamentos sem aguapé (teste de Tukey, $\mathrm{p}<0,05$ ) (Figura 2), onde o efluente tratado com macrófitas aquáticas apresentou menores valores de fósforo $\left(1,90 \pm 0,1 \mathrm{mg} \mathrm{L}^{-1}\right)$ em comparação com o tratamento sem aguapé $\left(2,28 \pm 0,2 \mathrm{mg} \mathrm{L}^{-1}\right)$.

A hipótese de que os primeiros quinze dias possam estar afetando os resultados do uso do aguapé na filtração do fósforo não se justifica, pois menores valores deste parâmetro também foram encontrados na terceira quinzena (teste de
Tabela 1 - Valores médio \pm desvio padrão das características limnológicas da água do efluente tratado com e sem presença de aguapé durante o período estudado ${ }^{(1)}$

\begin{tabular}{|c|c|c|c|}
\hline Variáveis & Horário & $\begin{array}{l}\text { Tratamento com } \\
\text { Aguapé }\end{array}$ & $\begin{array}{c}\text { *Média dos } \\
\text { tratamentos sem } \\
\text { Aguapé }\end{array}$ \\
\hline \multirow{2}{*}{ Temperatura $\left({ }^{\circ} \mathrm{C}\right)$} & Manhã & $27.93 \pm 1.10^{\mathrm{aA}}$ & $26.91 \pm 0.59 \mathrm{aB}$ \\
\hline & Tarde & $29.25 \pm 1.19 \mathrm{bA}$ & $28.10 \pm 0.79$ ьв \\
\hline \multirow{2}{*}{ Oxigenio dissolvido (mg L-1) } & Manhã & $6.00 \pm 0.22{ }^{\mathrm{aA}}$ & $6.29 \pm 0.22 \mathrm{aB}$ \\
\hline & Tarde & $6.49 \pm 0.20^{\mathrm{bA}}$ & $6.72 \pm 0.24 \mathrm{bA}$ \\
\hline \multirow{2}{*}{ pH } & Manhã & $6.93 \pm 0.32^{\mathrm{aA}}$ & $7.25 \pm 0.25$ bB \\
\hline & Tarde & $7.07 \pm 0.32^{\mathrm{aA}}$ & $7.25 \pm 0.25$ bB \\
\hline \multirow{2}{*}{ Amônia (mg L-1) } & Manhã & $0.21 \pm 0.12^{\mathrm{aA}}$ & $0.12 \pm 0.06^{\mathrm{bA}}$ \\
\hline & Tarde & $0.26 \pm 0.07 \mathrm{aB}$ & $0.20 \pm 0.06$ aв \\
\hline \multirow{2}{*}{ Alcalinidade (mg L-1) } & Manhã & $23.35 \pm 3.59 \mathrm{aA}$ & $24.67 \pm 3.63^{\mathrm{bA}}$ \\
\hline & Tarde & $23.92 \pm 1.70 \mathrm{aB}$ & $24.67 \pm 3.64$ bB \\
\hline \multirow{2}{*}{ Dureza $\left(\mathrm{mg} \mathrm{L}^{-1}\right)$} & Manhã & $20.17 \pm 2.12^{\mathrm{aA}}$ & $24.67 \pm 2.45^{\mathrm{bB}}$ \\
\hline & Tarde & $22.16 \pm 2.10^{\mathrm{aA}}$ & $26.67 \pm 2.56^{\mathrm{bB}}$ \\
\hline \multirow{2}{*}{ Fósforo (mg L-1) } & Manhã & $1.74 \pm 0.24$ aA & $2.17 \pm 0.22$ ьв \\
\hline & Tarde & $2.01 \pm 0.18^{\mathrm{aA}}$ & $2.46 \pm 0.24 \mathrm{bB}$ \\
\hline
\end{tabular}

(1)Valores seguidos pela mesma letra não diferem entre si pelo teste de Tukey, a 5\% de probabilidade. a-bComparação entre os horários dentro do mesmo tratamento. A-BComparação entre mesmo horário nos diferentes tratamentos. * Média dos dois tratamentos sem aguapé que não obtiveram valores com diferenças significativas (Teste de Tukey $>0,05$ )

Tabela 2 - Produção de biomassa do aguapé em cada etapa experimental

\begin{tabular}{ccc}
\hline Parâmetros & $\begin{array}{c}1^{\text {a }} \text { Quinzena } \\
\text { Maio }\end{array}$ & $\begin{array}{c}3^{\text {a }} \text { Quinzena } \\
\text { Junho }\end{array}$ \\
\hline Peso inicial $\left(\mathrm{kg} \mathrm{m}^{-2}\right)$ & 14,00 & 14,00 \\
*Peso final $\left(\mathrm{kg} \mathrm{m}^{-2}\right)$ & $31,64^{\text {a }}$ & $18,70^{\text {b }}$ \\
*Produção $\left(\mathrm{kg} \mathrm{m}^{-2}\right)$ & $21,64^{\text {a }}$ & $1,90^{\text {b }}$ \\
*Ganho diário $\left(\mathrm{g} \mathrm{dia}^{-1}\right)$ & $3,05^{\text {a }}$ & $0,48^{\text {b }}$ \\
\hline
\end{tabular}

*Letras diferentes indicam ocorrer diferenças significativas $(p<0,05)$.

Tukey, $\mathrm{p}=0,274$ ), diferindo estatisticamente das etapas onde só constava secção de alívio (Figura 2).

Independentemente do tratamento, não foram encontrados diferenças nos níveis de fósforo entre os horários de coleta (teste de Tukey, $\mathrm{p}=0,06$ ) (Tabela 1). Considerando o efeito da filtração do aguapé em cada secçáo experimental, observa-se declínio nos teores de fósforo da primeira a última unidade, onde os níveis iniciais e finais médios desta variável no canal oscilaram entre $2,25 \mathrm{mg} \mathrm{L}^{-1}$ e $1,81 \mathrm{mg} \mathrm{L}^{-1}$, respectivamente (teste de Tukey, $\mathrm{p}=0,048$ ). Quanto à biomassa de macrófitas, esta foi maior nos primeiros quinze dias do trabalho do que na terceira quinzena (teste de Bonferroni, $\mathrm{t}<0.05$ ). Os valores de produção de biomassa do aguapé, para cada etapa com presença deste, estáo dispostos na Tabela 2. Na primeira quinzena, estando o aguapé aclimatado ao ambiente, houve absorção dos nutrientes disponíveis no meio aquático, incrementando sua biomassa (Gentelini et al., 2008), porém, na $3^{a}$ quinzena a concentraçáo de fósforo aumentou e a biomassa de aguapé diminuiu. 


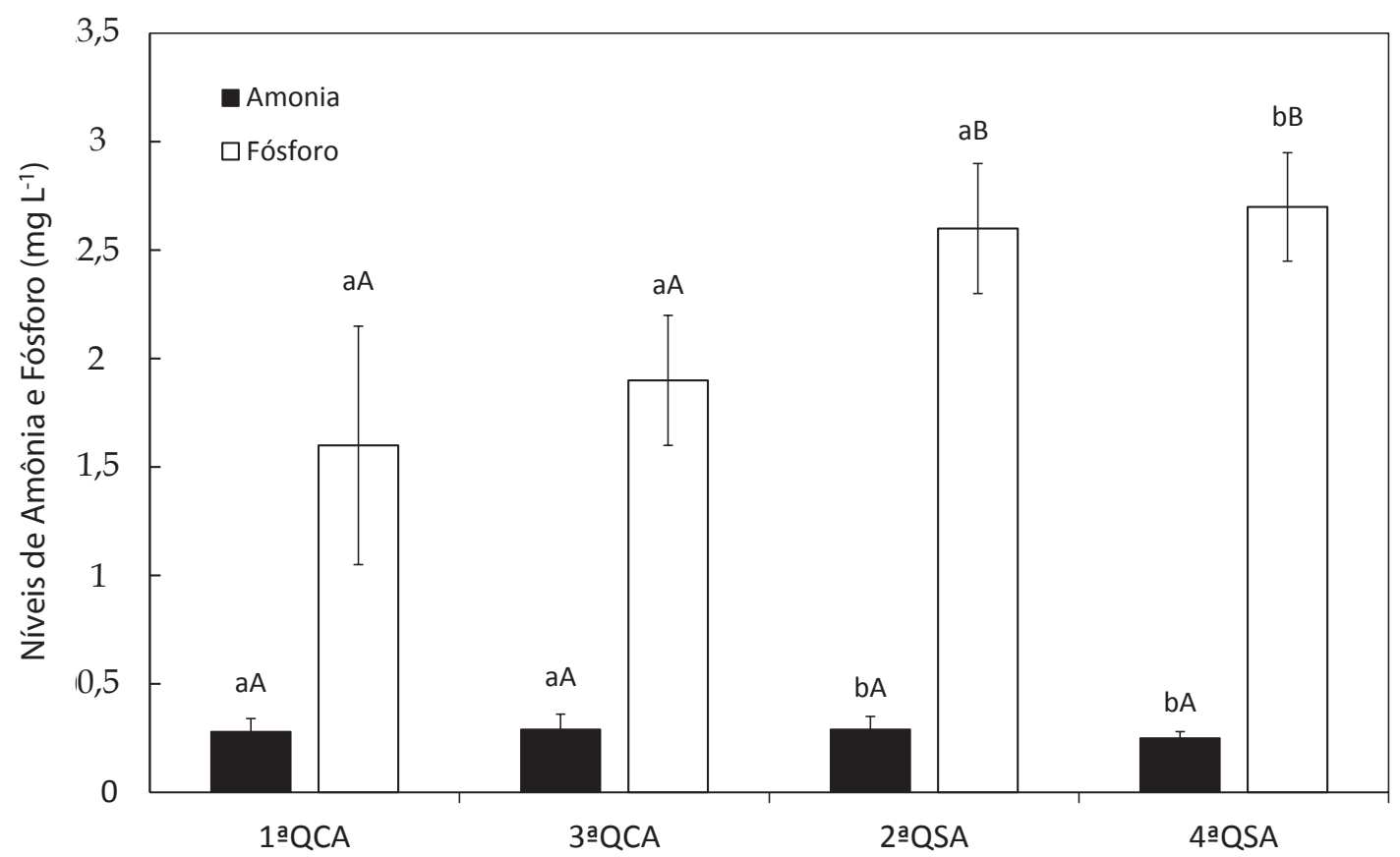

Figura 2 - Níveis de fósforo e amônia nos tratamentos com presença e sem presença de aguapé.

\section{DISCUSSÃO}

Os resultados para a temperatura contrastam com os encontrados por Gentelini et al. (2008) (17,8 à 19,8 ${ }^{\circ} \mathrm{C}$ e vazáo de 4,8 e $\left.12 \mathrm{~L} \mathrm{~min}^{-1}\right)$ e Henry-Silva e Camargo (2008) (26,5 ${ }^{\circ} \mathrm{C}$ e vazáo $1 \mathrm{~L} \mathrm{~min}^{-1}$ ), ambos observaram que a presença de macrófitas diminuíam a temperatura, possivelmente, devido o sombreamento da superfície e menor absorção de raios solares pela água (Martins e Pitelli 2005). Possivelmente, o aumento da vazáo nos canais (entre 4.200 e $4.800 \mathrm{~L} \mathrm{~min}^{-1}$ ) e a diminuição do tempo de resiliência da água em certo período do experimento possa ter contribuído para estas diferenças. Ocorre que devido à vazáo mais elevada, não houve tempo suficiente para que o sombreamento proporcionado pelos aguapés (crescimento vertical) diminuísse a temperatura da água.

Os níveis de oxigênio dissolvido observados nos tratamentos com e sem aguapés não diferiram significativamente, com exceçáo apenas do período matutino (Tabela 1), possivelmente devido o sombreamento da coluna d'água que inibe o desenvolvimento fitoplanctônico inicial e/ou à decomposição da matéria orgânica aderida ao sistema radicular do aguapé (Henry-Silva e Camargo 2008). Este fato foi comprovado por Reddy e Debusk (1985) em sistemas de tratamento de efluentes com diferentes macrófitas, por onde concluíram que diminuições das concentrações de oxigênio ocorreram pelo possível sombreamento na coluna da água e a decomposição da matéria orgânica.
Já Henry-Silva e Camargo (2006, 2008), constataram maior desenvolvimento de fitoplâncton em tanques sem macrófitas, o que, consequentemente, promoveu aumento dos teores de oxigênio dissolvido no ambiente ao longo do dia. Adicionalmente, a constante renovação e movimentação da água nos canais com vazâo acima de $4.000 \mathrm{~L} \mathrm{~h}^{-1}$ impulsionaram as trocas gasosas entre o meio aquático e o oxigênio atmosférico, possibilitando a obtenção de níveis acima de 6,0 $\mathrm{mg} \mathrm{L}^{-1}$.

A redução de $\mathrm{pH}$ ao longo dos dias no presente experimento obteve comportamento semelhante aos estudos de Henry-Silva e Camargo (2006) e Gentelini et al. (2008) após a passagem do efluente pelo sistema de tratamento com macrófitas aquáticas. Tal afirmação pode ser explicada pela remoção de bases para o crescimento do aguapé.

Os menores valores de dureza encontrados no sistema de tratamento com aguapé, se assemelham aos encontrados por Vieira et al. (2010), que comprovou a eficiência de remoçấo de impurezas na água utilizando a macrófita denominada taboa, Typha domingensis, como biofiltro, provavelmente devido a assimilação dos íons (cálcio e magnésio), proporcionado pela microbiota e macrófitas.

O fluxo contínuo da água e a presença do aguapé podem ter influenciado nas concentraçôes dos nutrientes, alterando assim a dinâmica limnológica do canal, caracterizando um ambiente com bom padrão de qualidade de água. 
Segundo estudos de Hurvitz et al. 1997; Pereira e Mercante 2005, é esperado elevaçẫo dos níveis de amônia durante o cultivo, devido o aumento da demanda de oxigênio e incremento da excreçấo por peixes, acúmulo de metabólitos proveniente da ração, ou ainda, maiores níveis de matéria orgânica provenientes da decomposição de raízes ou folhas de macrófitas e estresse do próprio vegetal em relação à velocidade da água no canal. Apesar desta afirmação é pouco provável que tenha contribuído negativamente no cultivo, já que os valores desta variável permaneceram dentro da faixa de tolerância para o cultivo da maioria de espécies de peixes de água doce em ambientes de confinamento, devendo-se em parte às condiçôes de renovação de água, poder filtrante do aguapé e a substituição destas a cada 15 dias.

A exemplo dos estudos realizados por Crema (2005), Henry-Silva e Camargo (2006) e Gentelini et al. (2008), aos quais obtiveram $43 \%, 82,0 \%$ e $43 \%$ e $71,6 \%$ de sucesso na remoção de nutrientes, respectivamente, o presente estudo comprova a eficiência destes vegetais na remoção de fósforo em $12,8 \%$ pela manhã e de $14,4 \%$ pela tarde, a mais que o sistema sem aguapé.

Embora, os valores referendados no experimento em questâo tenham sido menores que o de outros autores, é provável que o tempo de residência do efluente no sistema de fluxo contínuo esteja afetando o poder de filtração do aguapé. Alta vazão geralmente impede os processos de absorção de nutrientes e de sedimentaçáo do material particulado, fato comprovado por Sipaúba-Tavares et al. (2001), que verificaram acréscimo nos valores de nutrientes no efluente tratado de um sistema com elevado fluxo, tal fato pode ter contribuído também para a diminuição da capacidade filtrante da macrófita nas semanas finais do experimento.

Paralelamente, Sakadevan e Bavor (1999) observaram correlação positiva entre a eficiência na remoção de nutrientes pelas macrófitas aquáticas emersas e o tempo de residência do efluente. Assim, a vazão média de $4.400 \mathrm{~L} \mathrm{~h}^{-1}$ utilizada neste trabalho foi suficiente para atenuar os níveis de metabólitos nos efluentes de piscicultura, no entanto não dispensa o uso de aguapé, devido o poder adicional de filtragem deste vegetal, principalmente quando se utiliza a água destes ambientes para outras culturas.

Segundo Sipaúba-Tavares (2000), é possível que a $E$. crassipes ao atingir seu ponto de saturação, diminua o poder de absorção de nutrientes e não consiga remover metabólitos do meio aquático, situação esta comum quando se trabalha com macrófitas aquáticas em condiçôes de cativeiro. Desta forma pode-se afirmar que o uso de aguapés em sistemas de cultivo com fluxo contínuo possa estar limitado à variável tempo, pois estes mesmos autores recomendaram sua substituiçáo em período inferior a 30 dias (entre aclimatação e uso no cultivo).
$\mathrm{O}$ aumento da temperatura pode ter influenciado no incremento da biomassa durante a primeira etapa do experimento com presença de macrófitas. Segundo Pedralli (1996), a temperatura ideal para o desenvolvimento do aguapé está entre 25 e $31^{\circ} \mathrm{C}$. Corroborando com esta hipótese, Gentelini et al. (2008), utilizando o aguapé em sistema de tratamento de efluente de piscicultura orgânica, obteve no experimento uma produção média de $8,03 \mathrm{~kg} \mathrm{~m}^{-2}$, produção esta inferior à encontrada neste experimento, possivelmente devido a temperaturas baixas $\left(18,7^{\circ} \mathrm{C}\right)$. Além da temperatura, a disponibilidade da intensidade luminosa e concentraçôes de nutrientes como o fósforo podem ter influenciado na produtividade destas macrófitas (Sipaúba-Tavares et al. 2002).

Os resultados de desempenho dos peixes apresentaram valores inferiores aos obtidos em sistemas de cultivo com baixo fluxo de água e deve-se provavelmente ao maior gasto energético dos exemplares submetidos ao experimento, devido ao intenso movimento da coluna da água, ao quais os exemplares são submetidos em sistemas de fluxo contínuo (Arbeláez-Rojas et al. 2002).

Desta forma, o monitoramento e melhora dos parâmetros físico-químicos da água (oxigênio dissolvido, amônia, nitrito, fósforo, $\mathrm{pH}$ e temperatura) é prioritário para programa de arranjos produtivos locais, principalmente no Baixo São Francisco, que detém de uma grande rede de canais multiuso $(80 \mathrm{~km})$, sendo mal aproveitados para o cultivo de peixes, devido as dificuldades de acesso a informaçóes que possibilitem a prática desta atividade.

A busca por sistemas de cultivo economicamente e ambientalmente sustentáveis com maximização da biomassa e com finalidades diversas, como é o caso de canais de irrigação e de abastecimento devem ser prioridade em regióes semiáridas, por proporcionar melhor aproveitamento de estruturas já existentes, podendo gerar renda e emprego com a atividade de criação de peixes. Ademais, este sistema pode difundir a prática sustentável e manejo da qualidade de água com o uso adicional de macrófitas aquáticas, que possuem poder filtrante na remoção de nutrientes como o fósforo.

\section{CONCLUSÕES}

O aguapé se mostrou eficiente na remoção do fósforo, entretanto o uso desta macrófita não é recomendável na filtragem de amônia em ambientes com alto fluxo de água a exemplo de canais de abastecimento do presente estudo.

\section{AGRADECIMENTOS}

À CODEVASF - Companhia de Desenvolvimento dos Vales do São Francisco e do Parnaíba (base de Piscicultura de Betume) e ao apoio da Fundação de Amparo à Pesquisa de Alagoas- FAPEAL. 


\section{BIBLIOGRAFIA CITADA}

American Public Health Association (APHA). 1995. Standardmethods for the examination of water and wastewater. $19 \mathrm{ed}$. Washington, DC, 1995, 1134p.

Arbeláez-Rojas, G.A.; Fracalossi, D.M.; Fim, J.D.I. 2002. Composição corporal do tambaqui, Colossomamacropomum e matrinxá, Bryconcephalus, em sistema de cultivo intensivo, igarapé e semi-intensivo, viveiros. Revista Brasileira de Zootecnia, 31: 1059-1069.

Crema, L.C. 2005. Efluentes de tanques de criação de Tilápia do Nilo: Características limnológicas e eficiência de tratamento pelo Aguapé. Tese de Mestrado, Universidade Estadual Paulista, Jaboticabal, São Paulo. 63p.

Ferdoushi, Z.; Haque, F.; Khan, S.; Haque, M. 2008. The effect the two aquatic macrophytes floating (Lemna e Azolla) like biofilters of nitrogen and phosphate in fish ponds. Turkish Journal of Fisheries and Aquatic Sciences, 8:253-258.

Gentelini, A.L.; Gomes, S.D.; Feiden, A.; Zenatti, D.; Sampaio, S.C.; Coldebella, A. 2008. Produção de biomassa das macrófitas aquáticas Eichhornia crassipes (aguapé) e Egeria densa (egeria) em sistema de tratamento de efluente de piscicultura orgânica. Ciências Agrárias, 29: 441-448.

Gonçalves Júnior, A.C.; Lindino, C.A.; Rosa, M.F.; Bariccatti, R.; Gomes, G.D. 2008. Remoção de metais pesados tóxicos cádmio, chumbo e cromo em biofertilizante suíno utilizando macrófita aquática (Eichhornia crassipes) como bioindicador. Acta Scientiarum. Technology, 30: 9-14.

Henry-Silva, G.G.; Camargo, A.F.M. 2002. Valor nutritivo de macrófitas aquáticas flutuantes (Eichhornia crassipes, Pistiastratiotes e Salvinia molesta) utilizadas no tratamento de efluentes de aquicultura. Acta Scientiarum, 24: 36-48.

Henry-Silva, G.G.; Camargo, A.F.M. 2006. Efficiency of aquatic macrophytes to treat Nile tilapia pond effluents. Scientia Agricola, 63: 417-513.

Henry-Silva, G.G.; Camargo, A.F.M. 2008. Tratamento de efluentes de carcinicultura por macrófitas aquáticas flutuantes. Revista Brasileira de Zootecnia, 37: 181-188.

Hurvitz, A.; Bercovier, H.; Van Rinj, J. 1997. Effect of ammonia on the survival and the immune response of rainbow trout (Oncorhynchus mykiss, Walbaum) vaccinated against Streptococcus iniae. Fish \& Shellfish Imunology, 7: 45-53.

Klomjek, P.; Nitisoravut, S. 2005. Constructed wetland: a study of eight plant species under saline concitions. Chemosphere, 58: $585-593$
Lima, C.B.; Oliveira, E.G.; Araújo-Filho, J.M.; Santos, F.J.S.; Pereira, W.E. 2008. Qualidade da água em canais de irrigaçáo com cultivo intensivo de tilápia nilótica (Oreochromisniloticus). Revista Ciências Agronômicas, 39: 531-539.

Macedo, C.F.; Sipaúba-Tavares, L.H. 2010. Eutrofização e qualidade da água na piscicultura: consequências e recomendaçóes. Boletim do Instituto de Pesca, 26: 149-163.

Martins, T.; Pitelli, R.A. 2005. Efeitos do manejo de Eichhornia crassipes sobre a qualidade da água em condiçôes de mesocosmos. Planta Daninha, 23: 233-242.

Pedralli, G. 1996. Aguapé: biologia, manejo e uso sustentado. Estudos de Biologia, 4: 33-53.

Pereira, L.P.F.; Mercante, C.T.J. 2005. A Amônia nos sistemas de criação de peixes e seus efeitos sobre a qualidade da água. Uma revisão. Boletim do Instituto de Pesca, 31: 81-88.

Pompêo, M. 2008. Monitoramento e manejo de macrófitas aquáticas. Oecologia Brasiliensis, 12: 406-424.

Redding, T.A.; Midlen, A.B. 1992. Estudio de la producción piscícola en los canales de riesgo. FAO - Documento Técnico de Pesca, n.317, 114p.

Reddy, K. R.; Debusk, T. A. 1985. Nutrient removal potential of selected aquatic macrophytes. Journal of Environmental Quality, 14: 459-462.

Sakadevan, K.; Bavor, H.J. 1999. Nutrient removal mechanisms in constructed wetlands and sustainable water management. Water Science Technology, 40: 121-128.

Sipaúba-Tavares, L.H. 2000. Utilização de biofiltros em sistema de cultivo de peixes. Informe Agropecuário, 21: 38-43.

Sipaúba-Tavares, L.H.; Fávero, E.G.P.; Braga, F.M. 2001. Utilização de biofiltros de macrófitas como forma de minimizar os impactos causados pela aqüicultura. In: Seminário Internacional da Represa do Lobo-Broa, 2001, São Carlos. p.151.

Sipaúba-Tavares, L.H.; Favero, E.G.P.; Braga, F.M.S. 2002. Utilization of macrophyte biofilter in effluent from aquaculture: I.floating plant. Brazilian Journal of Biology, 62:713-723.

Sipaúba-Tavares, L.H.; Barros, A.F.; Braga, F.M.S. 2003. Effects of floating macrophyte cover on the water quality in fish pond Acta Scientiarum, 25: 101-106.

Vieira, F.; Silva, G.M.; Peres, J. P.; Alves, E.D.L. 2010. Análise da eficiência de remoção de impurezas na água: Utilização de lagoas de estabilização combinado com sistema Alagado. Enciclopédia Biosfera, 6: 1-8.

Recebido em 18/12/2012

Aceito em 01/07/2013 
